\title{
Coalbed methane genesis, occurrence and accumulation in China
}

\author{
Song Yan ${ }^{1,2 *}$ Liu Shaobo${ }^{1}$, Zhang Qun ${ }^{3}$, Tao Mingxin ${ }^{4}$, Zhao Mengjun ${ }^{1}$ and \\ Hong Feng ${ }^{1}$
}

${ }^{1}$ Research Institute of Petroleum Exploration \& Development, Beijing 100083, China

${ }^{2}$ China University of Petroleum, Beijing 102249, China

${ }^{3}$ Xi' an Research Institute of China Coal Technology \& Engineering Group Corp., Shaanxi 710077, China

${ }^{4}$ Beijing Normal University, Beijing 100875, China

(C) China University of Petroleum (Beijing) and Springer-Verlag Berlin Heidelberg 2012

\begin{abstract}
Coalbed methane (CBM) is an important type of unconventional gas. Commercial development of CBM in America has been very successful since the 1980s. The CBM industry in Australia and Canada has developed rapidly during the last decade. Commercial development of CBM in China started in the 1990s, and has made great progress. The geological theory of CBM in China has achieved great advancement in genesis, occurrence and accumulation. On the aspect of CBM genesis, five CBM genetic types (primary biogenic gas, secondary biogenic gas, thermal degradation gas, pyrolysis gas and mixed gas) are identified by studying the geochemical characteristics of CBM, and a tracing indicator system is established. The discovery of secondary biogenic gas in medium-high rank coal reservoirs has widened the potential of $\mathrm{CBM}$ resources. On the aspect of $\mathrm{CBM}$ occurrence, the gas adsorption regulation under combined action of temperature and pressure is revealed by conducting adsorption experiments of different coal ranks under varying temperature and pressure conditions. Besides, by applying the adsorption potential theory in CBM research, the adsorption model under combined action of temperature and pressure is established. The new model can predict CBM resources accurately, and overcome the limitation of the traditional Langmuir model which uses just a single factor to describe the adsorption characteristics of deep buried coal. On the aspect of CBM accumulation, it is proposed that there are three evolutionary stages during CBM accumulation, including gas generation and adsorption, unsaturated gas adsorption, gas desorption-diffusion and preservation. Controlled by tectonic evolution, hydrodynamics and sealing conditions, CBM tends to be regionally enriched in synclines. Advances in geological theory of CBM in China can not only improve understanding of natural gas, but also provide new ideas for further exploration of CBM.
\end{abstract}

Key words: China, coalbed methane, genetic type, secondary biogenic gas, adsorption model, syncline enrichment

\section{Introduction}

Coalbed methane (CBM) is an unconventional resource with great potential but a low level of development, and is also the most realistic additional energy source in China. The CBM development in China started in 1950s when CBM extraction was conducted just for the safety of coal mining. CBM exploration in China flourished with the introduction of advanced CBM development technology from abroad in the 1990s. Meanwhile more focus has been paid by the government to CBM exploration and development. The CBM industry in China developed rapidly in the last decade. By the end of 2010, there have been more than 5000 surface wells

* Corresponding author email: sya@petrochina.com.cn

Received December 13, 2011 drilled and the ground gas production has reached $1.5 \times 10^{9} \mathrm{~m}^{3}$ per year.

After the large scale CBM development in the San Juan, Black Warrior and north Appalachian basins since the 1980s, the Gas Research Institute of America conducted research to study the controlling factors of CBM enrichment and production. Through studying the controlling factors of CBM accumulation, tectonic evolution, and burial history of the San Juan Basin, Ayers (1991; 2002) delineated CBM zones with different enrichment degrees and established a formation model of CBM high production fairways, which was widely accepted and applied to CBM exploration. Subsequently, a lot of scholars and research institutes also presented similar controlling factors of CBM enrichment and high production by studying the similar zones with high production in the Black Warrior Basin and helped guiding the CBM exploration 
and development effectively.

Since the late 1980s, experiments on CBM exploration, development and related research work had been done in a lot of areas in China. Based on the CBM research in the Qinshui Basin, the controlling factors of CBM accumulation are presented, including hydrodynamics, effective thickness of overlying strata, seals, tectonic evolution and magma intrusion. The CBM enrichment zones in the southern Qinshui Basin are predicted to be located in an annular slope belt (Zhang et al, 2002; Song et al, 2007). Qin (2005) also put forward the key geological factors of CBM enrichment, based on research into favorable CBM enrichment areas in the Qinshui Basin. Yang and Tang (2000) suggested that a magmatic thermal event is a key controlling factor of CBM enrichment during their research on CBM in coal basins of North China.

There are abundant medium/high rank coal basins widely distributed in China. Comparing those with foreign CBM basins, the accumulation mechanism and key controlling factors of CBM in China are distinctive. In 2002 and 2009, there were two projects set up separately in the National Basic Research Program of China. One is "Basic studies of formation mechanisms and economic exploitation of coalbed gas reservoirs". The other is "Basic research on enrichment mechanisms and improving the exploitation efficiency of CBM reservoirs". After intensive study of high-rank CBM formation and distribution in China, the geologic theory on CBM genesis, accumulation and occurrence was established.

\section{Genesis of CBM}

The geochemical characteristics of CBM are different from conventional natural gas because of the differences in their genesis. Many studies have been done on the geochemical characteristics and genesis of conventional natural gas (Fu et al, 1990; Dai et al, 1992; Liu and $\mathrm{Xu}$, 1996; Qin, 2003), but few on CBM genesis. When the National Basic Research Project (CBM Project) was set up, the genesis classification of CBM is simple, and scholars thought just two genesis types of CBM made up the majority of CBM; biogenic gas and thermogenic gas. The biogenic gas is primary biogenic gas generated during the evolution from peat to lignite, while thermogenic gas is gas generated under regular thermal evolution from bituminite to anthracite. Because of some abnormal levels in stable carbon isotopes in CBM, Chinese scholars suggested that there are other genetic types of CBM besides biogenic gas and thermogenic gas (Scott et al, 1994), such as secondary biogenic gas (Guan et al, 1995), mixed genetic gas (Tao, 2005). To sum up, early research did not reveal all the genetic types of CBM, and the tracing indicators were limited to carbon isotopes and composition, which cannot meet the need for CBM resource evaluation (Zhang, 2002). After the first round of research on CBM funded by National Basic Research Program of China, the classification of CBM genesis type and tracing indicator system are established.

\subsection{Geochemical characteristics of CBM and its difference from conventional gas}

Because CBM mainly exists in coal beds, it is mainly made up of adsorbed gas without a secondary migration process. Hence, the geochemical characteristics of CBM differ from convention natural gas.

\subsubsection{Composition of CBM}

CBM is mainly composed of $\mathrm{CH}_{4}$, secondarily heavy hydrocarbon $\left(\mathrm{C}_{2+}\right), \mathrm{N}_{2}, \mathrm{CO}_{2}$ and other minor composition including $\mathrm{Ar}, \mathrm{H}_{2}, \mathrm{He}, \mathrm{H}_{2} \mathrm{~S}, \mathrm{SO}_{2}$, and $\mathrm{CO}$ (Tao et al, 2005). Based on the composition of $358 \mathrm{CBM}$ samples from different geological time and coal ranks, Zhang et al (2002) discovered that the $\mathrm{CH}_{4}$ content ranged from $66.5 \%$ to $99.98 \%$ and generally between $85 \%$ and $93 \%$. The $\mathrm{CO}_{2}$ content ranged from 0 to $35.6 \%$ and generally below $2 \%$. The $\mathrm{N}_{2}$ content varies greatly but generally below $10 \%$, and heavy hydrocarbon content varies with coal ranks. Scott and Zhou (1995) revealed that the CBM compositions and their average contents are $93.2 \% \mathrm{CH}_{4}, 2.6 \% \mathrm{C}_{2+}, 3.1 \% \mathrm{CO}_{2}$, and $1.1 \% \mathrm{~N}_{2}$, according to their analysis of 985 gas samples from CBM wells in America. However, conventional natural gas is composed of $\mathrm{CH}_{4}, \mathrm{C}_{2+}, \mathrm{CO}_{2}, \mathrm{~N}_{2}, \mathrm{H}_{2} \mathrm{~S}, \mathrm{H}_{2}, \mathrm{He}$, and Ar. The $\mathrm{CH}_{4}$ content is generally $85 \%-100 \%$. The change of composition content varies with the type of organic matter in source rocks and the degree of thermal evolution. It is inferred that the $\mathrm{CH}_{4}$ content is higher in CBM, usually dry gas or super dry gas (Fig. 1, Table 1).

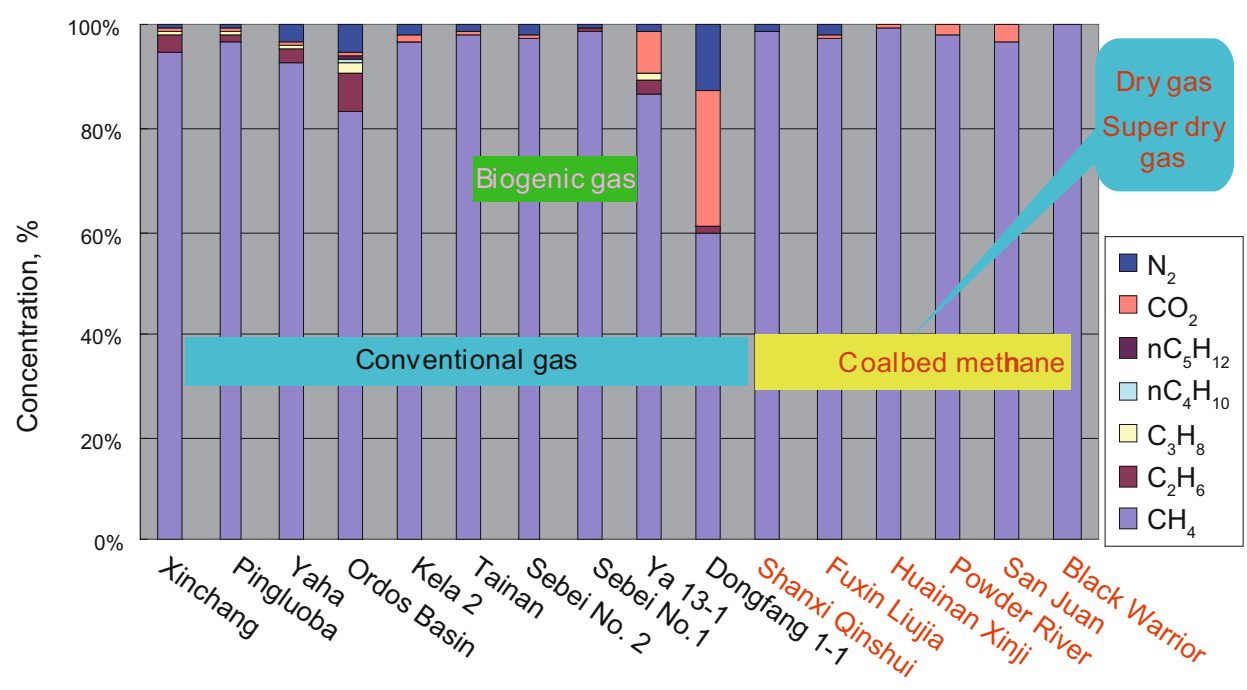

Fig. 1 Comparison of the composition of $\mathrm{CBM}$ and conventional gas 
Table 1 Statistics of classic coal-derived gas in China and CBM composition in China and America

\begin{tabular}{|c|c|c|c|c|c|c|c|c|c|c|c|}
\hline \multirow{2}{*}{ Type } & \multirow{2}{*}{ Basin } & \multirow{2}{*}{ Gas Field } & \multirow{2}{*}{$\begin{array}{c}\text { Main gas } \\
\text { strata }\end{array}$} & \multirow{2}{*}{ Reservoir } & \multicolumn{7}{|c|}{ Composition, $\%$} \\
\hline & & & & & $\mathrm{CH}_{4}$ & $\mathrm{C}_{2} \mathrm{H}_{6}$ & $\mathrm{C}_{3} \mathrm{H}_{8}$ & $n \mathrm{C}_{4} \mathrm{H}_{10}$ & $n \mathrm{C}_{5} \mathrm{H}_{12}$ & $\mathrm{CO}_{2}$ & $\mathrm{~N}_{2}$ \\
\hline \multirow{10}{*}{ Conventional gas } & \multirow{2}{*}{ Sichuan } & Xinchang & $\mathrm{J}_{2}, \mathrm{~J}_{3}$ & Sand & 94.19 & 3.6 & 0.66 & & & 0.68 & 0.57 \\
\hline & & Pingluoba & $\mathrm{T}_{3}$ & Sand & 96.38 & 2.04 & 0.26 & 0.04 & 0.01 & 0.47 & 0.56 \\
\hline & Ordos & Sulige et al & $\mathrm{P}$ & Sand & 90.8 & 2.74 & 0.51 & 0.1 & & 1.1 & 2.73 \\
\hline & \multirow{2}{*}{ Tarim } & Yaha & $E, N_{1} j$ & Sand & 82.32 & 7.45 & 2.51 & 0.62 & 0.2 & 1.13 & 4.91 \\
\hline & & Kela 2 & $\mathrm{~K}, \mathrm{E}$ & Sand & 96.58 & 0.48 & 0.08 & 0 & 0 & 1.07 & 1.76 \\
\hline & \multirow{3}{*}{ Qaidam } & Tainan & Q & Sand & 99.09 & 0.05 & 0.02 & & & 0.59 & 0.87 \\
\hline & & Sebei No.2 & Q & Sand & 98 & 0.16 & 0.04 & & & 0.41 & 2.11 \\
\hline & & Sebei No.1 & Q & Sand & 99.24 & 0.06 & 0.02 & & & & 0.68 \\
\hline & \multirow{2}{*}{ Yingqiong } & Ya 13-1 & $\mathrm{E}$ & Sand & 86.3 & 2.69 & 1.15 & 0.29 & 0.08 & 8.12 & 1.08 \\
\hline & & East 1-1 & $\mathrm{N}$ & Sand & 59.83 & 0.98 & 0.27 & 0.07 & 0.07 & 25.9 & 12.89 \\
\hline \multirow{6}{*}{ Coalbed methane } & Qinshui & Jincheng & $\mathrm{P}$ & Coal & 98.87 & 0 & 0 & 0 & 0 & 0.15 & 0.94 \\
\hline & Fuxin & Liujia & $\mathrm{K}$ & Coal & 97.76 & 0.02 & 0 & 0 & 0 & 0.79 & 1.43 \\
\hline & Huainan & Xinji & $\mathrm{P}$ & Coal & 99.75 & 0 & 0 & 0 & 0 & 0.2 & \\
\hline & Powder river & Powder river & $\mathrm{E}$ & Coal & 98.6 & 0 & 0 & 0 & 0 & 1.4 & \\
\hline & San Juan & San Juan & $\mathrm{K}$ & Coal & 97 & 0 & 0 & 0 & 0 & 3 & \\
\hline & Black warrior & Black warrior & $\mathrm{C}$ & Coal & 99.64 & 0 & 0 & 0 & 0 & & \\
\hline
\end{tabular}

\subsubsection{Isotope characteristics of CBM}

Research on the isotope geochemical characteristics of CBM has seldom been documented. Dai et al (1986) started to study isotopic geochemistry of CBM in China in 1980s. After testing and analyzing $42 \mathrm{CBM}$ samples from eight provinces, it is found that the value of $\delta^{13} \mathrm{C}_{1}$ is $-66.9 \% 0--24.9 \%$ o (PDB). Tao et al $(2005 ; 2007)$ obtained the geochemical characteristics of CBM as Table 1, by studying the isotopic geochemistry of samples from the Xinji Coalmine in Anhui province, the Liyazhuang Coalmine in Shanxi province and the Enhong Coalmine in Yunnan province (Table 2).

Based on the CBM isotope geochemical characteristics obtained by foreign scholars, it is discovered that the $\delta^{13} \mathrm{C}_{1}$ value of CBM is about $-80 \%--16.8 \%$ o $\mathrm{PDB}$ ), $\delta \mathrm{D}_{\mathrm{CH}_{4}}$ is about $-415 \% 0--117 \%$ ( $\mathrm{SMOW}$ ), $\delta^{13} \mathrm{C}$ value of $\mathrm{CO}_{2}$ is $-39 \%$ \% $-+18.6 \%$ (PDB). However, for conventional coal-type gas, the $\delta^{13} \mathrm{C}_{1}$ value is $-43 \%$ - $-10 \%$ (PDB), the $\delta^{13} \mathrm{C}_{1}$ value of oil-type gas is about $-55 \%--30 \%$ (PDB) (Dai et al, 1992). So, comparing with conventional gas, the carbon isotope ratio of $\mathrm{CH}_{4}$ in $\mathrm{CBM}$ is lighter than that of conventional gas (Fig. 2). Song et al (2010) draw the same conclusion by statistics of $\delta^{13} \mathrm{C}_{1}$ value of coal-type gas and CBM from Australia and China (Table 2).

The main reasons of the difference in carbon isotope levels of $\mathrm{CH}_{4}$ between $\mathrm{CBM}$ and conventional gas are desorption, biological action and hydrodynamics of CBM.

Desorption: CBM exists in coal beds in an adsorbed state. Desorption and diffusion of gas occurrs with changes of temperature and pressure, and gas enters pore spaces and fractures. During the process of CBM desorption, the desorption of heavy hydrocarbon is more difficult than CBM, and ${ }^{13} \mathrm{CH}_{4}$ is more difficult to desorb than ${ }^{12} \mathrm{CH}_{4}$. Therefore, the isotope fractionation effect often occurs in desorption, that is $\delta^{13} \mathrm{C}_{1}$ value of earlier desorbed CBM is relatively lighter, and the $\delta^{13} \mathrm{C}_{1}$ value of residual CBM is relatively heavier (Song et al, 2010; Gao et al, 2002).

Biological action: It is deemed by some scholars that the $\delta^{13} \mathrm{C}_{1}$ value of CBM is relatively lighter because of the mix of biogenic gas (Song et al, 2010; Gao et al, 2002; Liu et al, 1997). The $\delta^{13} \mathrm{C}_{1}$ value of biogenic gas is generally below $-55 \%$ (Dai et al, 1992), showing light isotope characteristics. So it is easily understood that the $\delta^{13} \mathrm{C}_{1}$ value of CBM lightened when biogenic gas mixed in. There are two possible origins for biogenic gas in coal beds. One is biological gas generated during the biochemical coalification stage, and remained in coal beds with the coalification. The other is biological gas formed by organic matter degradation with the bacteria entering coal beds along fractures with surface water. The mix of biogenic gas of two origins (mainly the degradation origin) and thermogenic methane during coalification resulted in the lightening of $\delta^{13} \mathrm{C}_{1}$ value (Liu et al, 1997).

Hydrodynamics: Partially oxidized and dissolved methane in water migrates and diffuses with hydrodynamics, causing large decrease of $\mathrm{CH}_{4}$. Meanwhile, the adsorbed gas in the coal beds started to desorb, dissolve and migrate. The ${ }^{13} \mathrm{CH}_{4}$ is dissolved preferentially and migrates with water, while ${ }^{12} \mathrm{CH}_{4}$ remained in place, leading to the lightening of the $\delta^{13} \mathrm{C}_{1}$ value (Fu et al, 2003). The $\delta^{13} \mathrm{C}_{1}$ became lighter with enrichment of ${ }^{12} \mathrm{CH}_{4}$ caused by the cumulative effect. In North 
Table 2 Statistics of isotope value of CBM from different basins

\begin{tabular}{|c|c|c|c|c|}
\hline \multirow{2}{*}{ Basin (Region) } & \multicolumn{4}{|c|}{ Isotope values } \\
\hline & $\delta^{13} \mathrm{C}_{1}(\mathrm{PDB}), \%$ & $\delta^{13} \mathrm{C}_{2}(\mathrm{PDB}), \%$ & $\delta^{13} \mathrm{C}_{\mathrm{CO}_{2}}(\mathrm{PDB}), \%$ & $\delta \mathrm{D}_{\mathrm{CH}_{4}}(\mathrm{SMOW}), \%$ \\
\hline Foreign coalbed methane basins & $-80--16.8$ & $-32.9--22.8$ & $-26-+18.6$ & $-333--117$ \\
\hline Sydney and Bowen basins in Australia & $-78.9--18.0$ & & $-15.5-+16.7$ & $-255--152$ \\
\hline Upper Silesian and Lublin basins in Poland & $-67.3--52.5$ & & & -201 \\
\hline Zonguldak Basin in Turkey & $-51.1--48.3$ & $-37.9--25.3$ & & $-190--178$ \\
\hline Elk Valley coal field in Canada & $-51.8--65.4$ & & & $-303--415$ \\
\hline Ruhr Basin in Germany & $-40.0--57.3$ & & & $-175--201$ \\
\hline China & $-66.9--24.9$ & & & \\
\hline Kailuan and Huainan coal field & $-73.1--30.1$ & & & \\
\hline Southern of Qinshui Basin & $-55--20.8$ & & & \\
\hline Xinji & $-50.7--61.3$ & $-15.9--26.7$ & $-6.0--39.0$ & \\
\hline
\end{tabular}

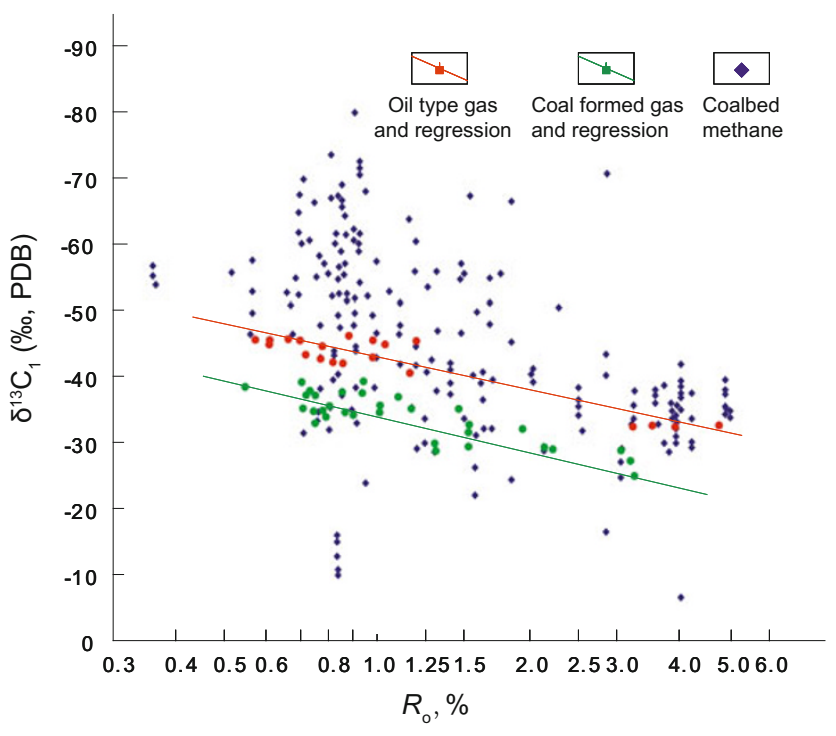

Fig. 2 Comparison of $\delta^{13} \mathrm{C}_{1}$ value between $\mathrm{CBM}$ and conventional gas

China, hydrodynamics in the Taiyuan Formation are stronger than the Shanxi Formation. So the $\delta^{13} \mathrm{C}_{1}$ value in the Taiyuan Formation is lighter than that of the Shanxi Formation. For example, in the Wubao area of the Ordos Basin, the $\delta^{13} \mathrm{C}_{1}$ value of 3\# coal seams of the Shanxi Formation is $-38.2 \%$ \% $(\mathrm{PDB})$ and the $\delta^{13} \mathrm{C}_{1}$ value of $10 \#$ coal seams of the Taiyuan Formation is $-46.3 \%$ (PDB). In the Jinshi 2 well of the Qinshui Basin, the $\delta^{13} \mathrm{C}_{1}$ values of 3\# coal seams of the Shanxi Formation and 15\# coal seams of the Taiyuan Formation are $31.8 \%$ and $-32.1 \%$ (PDB) respectively. In Jinshi 3 well, the values are $-33.6 \%$ (PDB) and $-35.4 \%$ (PDB) respectively. Furthermore, the phenomenon is also testified by experiment. The $\delta^{13} \mathrm{C}_{1}$ value of natural gas changed from $-40.5 \%$ (PDB) to $-48.3 \%$ ( $\mathrm{PDB}$ ) under the condition of long term leaching by distilled water at ordinary temperature. The lightening degree of the $\delta^{13} \mathrm{C}_{1}$ value tends to increase with the increase of leaching time (Song et al, 2010).

\subsection{Genetic type and tracing indicator of CBM}

The determination of CBM genesis type is the basis of CBM geology research. The international classification on CBM genesis type only considers simple factors and lacks systematic analysis. This paper presents a systematic classification for CBM genesis type based on experimental analysis of carbon isotopes, hydrogen isotopes and $R_{\mathrm{o}}$ index. Five CBM genetic types are identified; primary biogenic gas, secondary biogenic gas, thermal degradation gas, thermal cracking gas and mixed genetic gas and the relevant tracing indicator system is established.

\subsubsection{Primary biogenic gas}

The organic matter in the immature thermal evolution stage can generate biogenic gas because of microorganism activity. The mechanisms include zymosis of microorganisms on acetic acid and the $\mathrm{CO}_{2}$ reduction of methanobacteria, which is the main way. In the process of biogenic gas generation, because of shallow burial depth and low pressure of peat, the pore spaces were mostly occupied by water with little adsorption. Thus, the primary biogenic gas was distributed or dissolved in formation water which will be expelled from the coal bed during compaction and coalification. It is generally acknowledged that primary biogenic gas is not often preserved in later coal beds (Scott et al, 1994). Dai et al $(1992 ; 2008)$ presented that the identifying standard of biogenic gas included that $\mathrm{CH}_{4}$ is a major component, heavy hydrocarbon is below $0.5 \%$, and $\delta^{13} \mathrm{C}_{1}$ is no more than $-55 \%$ o (PDB). Based on previous research and the study in Shaer Lake of Xinjiang province, Tao et $\mathrm{al}^{1}$ suggested that the tracing index of primary biogenic gas included that $\delta^{13} \mathrm{C}_{1}$ is below $-55 \%$ ( $\left.\mathrm{PDB}\right), \delta \mathrm{D}_{\mathrm{CH}_{4}}$ is between $-(225 \pm 25) \%$ (SMOW), $\mathrm{C}_{1} / \mathrm{C}_{1-n}$ is no less than $0.99, \mathrm{C}_{2}$ is no more than $0.2 \%$, and $R_{0}$ is no more than $0.5 \%$.

\subsubsection{Secondary biogenic gas}

When the thermal evolution of coal exceeds the primary

${ }^{1}$ Tao Mingxin et al. Formation and evolution, genesis types and resource of coalbed methane. Internal Report. 2008 (in Chinese) 
biogenic stage, secondary biogenic gas is generated by microorganisms from $\mathrm{CO}_{2}, \mathrm{H}_{2}$, acetic acid, and methyl group. The generation conditions for secondary biogenic gas is that coal beds are uplifted closer to the surface, and bacteria permeated into coal beds with surface water and bred.

Research on secondary biogenic gas by international academic groups mainly focused on gas geochemistry. Recent research in China has achieved progress on the organic geochemical characteristics and evidence of microorganism degradation activity, source materials of secondary biogenic gas, its formation ways, tectonic conditions, and microbial population in coal beds. Based on experiments with microorganisms in coal beds, the mechanism of formation of secondary biogenic gas was first proposed and the tracing indicator of secondary biogenic gas is as follows: $\delta^{13} \mathrm{C}_{1}$ is no more than $-55 \%$ o $(\mathrm{PDB}), \delta \mathrm{D}_{\mathrm{CH}_{4}}$ is between $-(225 \pm 25) \%$ (SMOW), $\mathrm{C}_{1} / \mathrm{C}_{1+2}$ is no less than $0.99, \mathrm{C}_{2}$ is no more than $0.2 \%$ and $R_{\mathrm{o}}$ is more than $0.5 \%$.

\subsubsection{Thermal degradation gas}

The thermal degradation gas is generated under thermal action when organic matter is in mature to over-mature stage. Therefore, the thermal degradation gas tends to be generated easily in coal bed with medium-low coal rank. Little research has been done on the geochemical characteristics of thermal degradation gas and the identifying indicators. After systematic analysis of geochemical characteristics of thermal degradation gas, scholars in China presented the geochemical identifying indicators of CBM as follows: $\delta^{13} \mathrm{C}_{1}$ is more than $-55 \%$ (between $-50 \%$ and $-35 \%$ ) (PDB), $\delta \mathrm{D}_{\mathrm{CH}_{4}}$ is no less than $-250 \%$ o (SMOW), $\delta^{13} \mathrm{C}_{1}$ and $\delta \mathrm{D}_{\mathrm{CH}_{4}}$ has a positive correlation, $\mathrm{C}_{1} / \mathrm{C}_{1-n}$ is no more than 0.95 , the mean content of $\mathrm{CO}_{2}$ is about $4 \%$, $\mathrm{CDMI}\left(\mathrm{CO}_{2}-\mathrm{CH}_{4}\right.$ index, i.e., $\left.\left[\mathrm{CO}_{2} /\left(\mathrm{CO}_{2}+\mathrm{CH}_{4}\right)\right] 100 \%\right)$ is no more than $90 \%, R_{\mathrm{o}}$ is between $0.5 \%$ and $2.0 \%$. The CBM of Baojishan coalmine of Gansu Province in China belongs to thermal degradation gas type.

\subsubsection{Pyrolysis gas}

When organic matter reached over-mature stage, it is easy to generate pyrolysis gas, especially in high rank coal seams. Pyrolysis gas is a sub-type CBM of thermal genetic gas classified in recent years. The identifying indicators for pyrolysis gas is as follows: $\delta^{13} \mathrm{C}_{1}$ is more than $-40 \%$, $\delta \mathrm{D}_{\mathrm{CH}_{4}}$ is more than $-200 \%$ o (SMOW), $\delta^{13} \mathrm{C}_{1}$ and $\delta \mathrm{D}_{\mathrm{CH}_{4}}$ has a positive correlation, $\mathrm{C}_{1} / \mathrm{C}_{1+2}$ is no less than $0.99, \mathrm{C}_{1} / \mathrm{C}_{2}$ is no less than 3300 , CDMI is no more than $0.15 \%, R_{\mathrm{o}}$ is more than 2.0\%. The CBM of the Qinshui Basin in China belongs to this type.

\subsubsection{Mixed genetic gas}

Mixed genetic gas means a mixture of gas of different genesis types, showing different geochemical characteristics from single genesis type gas. The characteristics of mixed genetic gas is as follows: the value of $\delta^{13} \mathrm{C}_{1}$ is no less than $-55 \%$ o (PDB), $\delta \mathrm{D}_{\mathrm{CH}_{4}}$ is between $-250 \%$ and $-150 \%$, $\delta^{13} \mathrm{C}_{2}$ value is between $-27 \%$ and $-15 \%$ ( $\mathrm{PDB}), \delta^{13} \mathrm{C}_{\mathrm{CO}_{2}}$ value is between $-(22 \pm 18) \%$ o, $\mathrm{C}_{1} / \mathrm{C}_{1+2}$ is no less than 0.95 , CDMI value is between $0.5 \%$ and $5 \%$, and $R_{0}$ is more than $0.5 \%$. The $\delta^{13} \mathrm{C}_{1}$ value of gas samples from the Xinji coalmine in the Huainan area is between $-50.7 \%$ and $-61.3 \%$ (PDB), with a mean value of $56.6 \%$ (PDB). The $\delta^{13} \mathrm{C}_{2}$ value is between $-15.9 \%$ and $-26.7 \%$ (PDB) with a mean value of $-21.4 \%$. To sum up, a very high level of methane shows biogenic genesis, ethane is a sign of thermal genesis, $\mathrm{N}_{2}$ mainly comes from atmosphere and has the characteristics of mixed genesis gas.

Different genetic types of CBM can be classified according to different indicators (Table 3). Secondary biogenic gas exists in low rank coal basins abroad, such as the San Juan Basin (Scott et al, 1994). However, secondary biogenic gas is identified in medium-high rank coal basins of the Liyazhuang coalmine in Shanxi province and the Enhong coalmine in Yunnan province of China, with a resource contribution more than 50\% (Fig. 3) (Tao et al, 2005; 2007). Moreover, secondary biogenic gas was first identified in medium-high rank coal seams, which has significant meaning on broadening the CBM exploration area and evaluating CBM resources.

Table 3 Genetic types of CBM and geochemical tracing indicator

\begin{tabular}{cccccccc}
\hline \multirow{2}{*}{ Genetic types } & \multicolumn{7}{c}{ Geochemical tracing indicators } \\
\cline { 2 - 7 } & $R_{\mathrm{o}, \%}$ & $\begin{array}{c}\delta^{13} \mathrm{C}_{1}(\mathrm{PDB}) \\
\%\end{array}$ & $\begin{array}{c}\delta^{13} \mathrm{C}_{2}(\mathrm{PDB}) \\
\%\end{array}$ & $\begin{array}{c}\delta \mathrm{D}_{\mathrm{CH}_{4}}(\mathrm{SMOW}) \\
\%\end{array}$ & $\begin{array}{c}\delta^{13} \mathrm{C}_{\mathrm{CO}_{2}}(\mathrm{PDB}) \\
\%\end{array}$ & $\mathrm{C}_{1} / \mathrm{C}_{1+2}$ & $\begin{array}{c}\mathrm{CDMI} \\
\%\end{array}$ \\
\hline Primary biogenic gas & $\leq 0.5$ & $<-55$ & - & $-(225 \pm 25)$ & - & $\geq 0.99$ & - \\
Secondary biogenic gas & $>0.5$ & $\leq-55$ & - & $-(225 \pm 25)$ & - & $\geq 0.99$ & - \\
Thermal degradation gas & $0.5-2$ & $>-55$ & - & $\geq-250$ & - & $\leq 0.95$ & $\leq 90$ \\
Pyrolysis gas & $>2.0$ & $>-40$ & - & $>-200$ & - & $\geq 0.99$ & $\leq 0.15$ \\
Mixed genetic gas & $>0.5$ & $\geq-55$ & $-27--15$ & $-250--150$ & $-(22 \pm 18)$ & $\geq 0.95$ & $0.5-5$ \\
\hline
\end{tabular}

\section{Occurrence of CBM}

The difference between CBM and conventional gas is that CBM exists as adsorbed, free and dissolved gas in coal beds. Gas generated by coal beds is initially in the adsorbed form, and then it exists as free gas, and soluble gas in coal beds.
The three forms of gas keep in a dynamic balancing state. Although CBM exists as three forms, for the medium-high rank coals, adsorbed gas is the dominant form accounting for $95 \%$ of CBM.

The adsorption capacity of coal depends on the petrological composition, chemical structure, coal rank, 


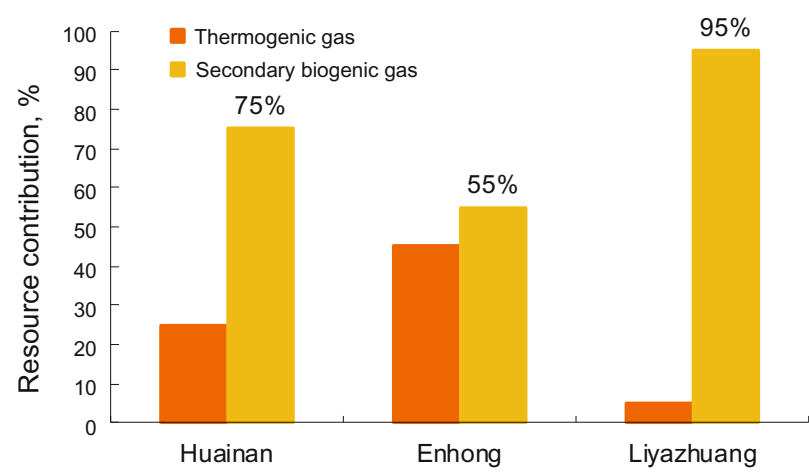

Fig. 3 Estimation of contributions of secondary biogenic gas to resources

water content and other factors of coal beds. The gas content of a coal reservoir is controlled by adsorption, temperature, pressure and their interaction. When evaluating the adsorption capacity of coals, the Langmuir equation is usually followed. However, the Langmuir equation only took single factor into consideration, and the premise is that coal samples are moisture-free or dry. Therefore, this model cannot reflect the variation of $\mathrm{CBM}$ adsorption with the change of temperature and pressure, which results in inaccuracy of $\mathrm{CBM}$ resource evaluation. Scholars in China further corrected the model after the research on adsorption characteristics under equilibrium water conditions, and made the adsorption evaluation more reasonable (Qin, 2003). Nevertheless, it cannot be explained the effect of underground temperature and pressure on CBM adsorption. In this paper, the CBM adsorption regulation under the interaction of temperature and pressure is discovered through adsorption experiments of metamorphic coals at varying temperatures and pressures. Then adsorption potential theory is initially applied to CBM research, and the adsorption model under interaction of temperature and
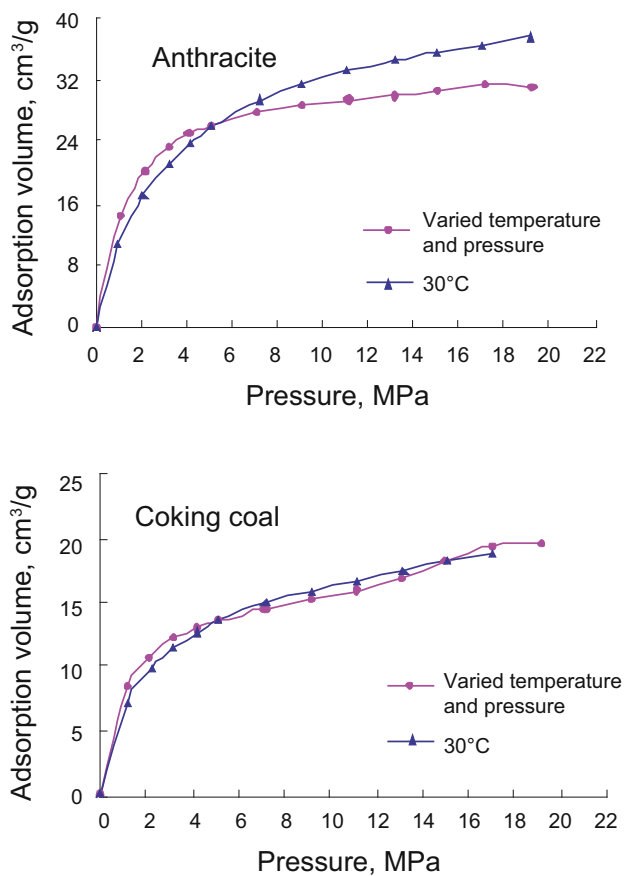

pressure is established, which provides scientific proof for CBM resource evaluation.

\subsection{Comparison between adsorption under varying temperature and pressure and isothermal adsorption of coals}

Temperature and pressure are two important parameters for the mathematic models which are used to describe adsorption of coal. The Langmuir adsorption model only considers adsorption volume under different pressure conditions, and the adsorption volume increases logarithmically with increasing pressure. In fact, temperature and pressure vary in different environments. Compared with a single factor, the effect of the simultaneous variation of temperature and pressure on adsorption capacity is different. This can be demonstrated by adsorption experiments on coal samples of different ranks at varying temperatures and pressures (Fig. 4). 1) When the temperature of varying temperature and pressure experiment is lower than that of an isothermal experiment, $30^{\circ} \mathrm{C}$, the adsorption volumes of anthracite, lean coal and coking coal at varying temperature and pressure are higher than the isothermal adsorption volumes under the same pressure condition. However, the adsorption volume of long-flame coal at varying temperature and pressure is always higher than the isothermal adsorption volume at the same pressure. 2) When the experiment conditions of varying temperature and pressure and isothermal adsorption are the same with the temperature of $30^{\circ} \mathrm{C}$ and pressure of $5 \mathrm{MPa}$, the adsorption curves of anthracite, lean coal and coking coal cross (Fig. 4), and the adsorption volumes are the same. However, for long-flame coal, the adsorption volume at varying temperature and pressure is greater than that of isothermal adsorption. 3) When the temperature of adsorption experiment at varying temperature and pressure is higher than
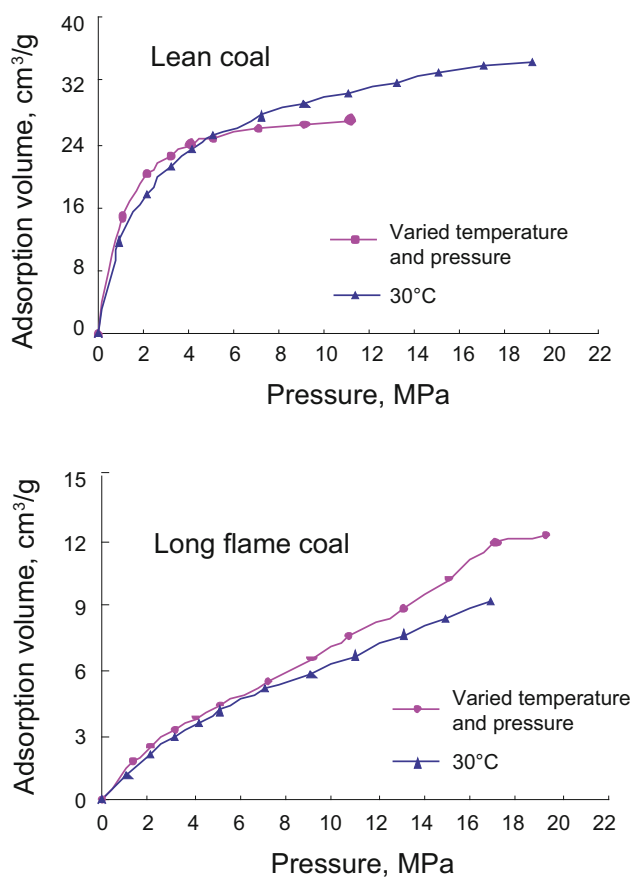

Fig. 4 Comparison of adsorption curves between varying temperature and pressure and isothermal adsorption at $30^{\circ} \mathrm{C}($ the long flame coal sample is from the Dongsheng coal field, the coking coal sample is from the Hedong coal field, and the lean coal and anthracite are from the Qinshui Basin) 
$30^{\circ} \mathrm{C}$, the adsorption volumes of anthracite and lean coals at varying temperature and pressure are significantly less than the isothermal adsorption volume at the same pressure. But when the temperature increased to $60^{\circ} \mathrm{C}$ and pressure increased to $15 \mathrm{MPa}$, the adsorption volume of coking coal at varying temperature and pressure becomes greater than the isothermal adsorption volume at the same pressure. 4) From the change of different coal types, the increase of adsorption volume for long-flame coal is greater than that of anthracite, lean coal and coking coal.

\subsection{Temperature and pressure comprehensive adsorption model}

Under geological conditions, temperature and pressure of coal beds vary simultaneously with depth. For a single factor, if ignoring the water content of coal beds, the adsorption capacity increased with the increasing temperature and pressure (Clarkson et al, 1997). If considering both temperature and pressure and their interactions, the description for coal bed adsorption will become complicated. So far, there is still not a more accurate adsorption model considering multiple factors than the Langmuir model (Clarkson et al, 1997; Weishauptova and Medek, 1998; Chen et al, 1998). The Langmuir adsorption model to describe the isothermal adsorption process of coal bed is still the most widely applied model in the CBM field (Ruppel et al, 1974). Based on the study of high rank coal adsorption at different depths, Song et al (2010) discovered that the adsorption peak of methane appeared at 1,500 $\mathrm{m}$, and then it started to decrease. Zhang et $\mathrm{al}^{2}$ discovered that the isothermal adsorption of ultra-low and ultra-high rank metamorphic coal is not consistent with the Langmuir model, which indicated that the Langmuir model has limitations. Based on further research, Zhang et $\mathrm{al}^{2}$ initially established the CBM adsorption model with interaction of temperature and pressure. The model is a significant step in adsorption theory research of CBM to overcome the shortcomings of the Langmuir model.

The first step for the establishment of adsorption model is obtaining the characteristic curves of methane based on adsorption experiments of coals with different ranks. The curve shows that the volumes of adsorption phase and adsorption potential have a logarithmic relationship, and the correlation coefficients are both greater than 0.99 . If using adsorption volume to replace the volume of adsorption phase, the relationship of adsorption volume, temperature and pressure can be described as follows:

$$
R T \ln \left(\frac{P T^{2.7}}{P T_{\mathrm{c}}^{2.7}}\right)=a \ln V+b
$$

Taking underground conditions into consideration, the coal adsorption model at varying temperature and pressure is obtained as follows:

$$
\ln V=A^{\prime} T[2.7 \ln T-\ln P-12.6603]+B^{\prime}
$$

\footnotetext{
${ }^{2}$ Zhang Qun et al. Adsorption characteristics and occurrence mechanisms of CBM. Internal Report. 2008
}

$A^{\prime}, B^{\prime}$ in the equation above is constant term, when $T$ is fixed, the model can be simplified as,

$$
\begin{aligned}
& \qquad \begin{array}{l}
\ln V=A \ln P+B \\
\text { and } A=-A^{\prime} T \\
\qquad B=A^{\prime} T \times 2.7 \ln T-A^{\prime} T \times 12.6603+B^{\prime},
\end{array}
\end{aligned}
$$

The simplified model can describe the relationship of pressure and adsorption volume. Theoretically, it is favorable to describe coal isothermal adsorption. The verification of the model by adsorption experiments showed that the data calculated by the temperature and pressure comprehensive adsorption model are more accurate than those using the Langmuir model with an error below 3\%.

\subsection{Application and significance of the temperature and pressure comprehensive model}

With the temperature and pressure comprehensive adsorption model, the adsorption volume at different temperatures can be predicted using the adsorption data at a given temperature. For example, the isothermal adsorption data of a given temperature $T_{1}$ are known. Constants $A$ and $B$ can be calculated using Eq. (2). Then using Eqs. (3) and (4) and temperature $T_{2}, A^{\prime}$ and $B^{\prime}$ can be calculated. Finally the corresponding adsorption volume can be calculated using Eq. (1), that is, the isothermal adsorption volume under $T_{2}$. The application of this method can theoretically calculate the adsorption volume at any temperature and pressure based on one group of isothermal data, which contributes to the prediction of gas content in coal reservoirs.

The temperature and pressure comprehensive adsorption model is applicable to adsorption volume calculation of different burial depths, and is suitable for different coals (from ultra-low rank coal to ultra-high rank coal). The prediction of gas adsorption volume under geologic conditions is more accurate than using the Langmuir model. Thus, the previous view of adsorption volume increasing with burial depth was changed, and the accuracy of resource prediction increased (Fig. 5). Therefore, this model is of great importance for $\mathrm{CBM}$ resource evaluation.

\section{CBM accumulation and enrichment}

The research on CBM accumulation mechanisms abroad is established on medium-low rank coal-bearing basins. In China, the research on CBM accumulation has been flourishing recently, and new concepts have been proposed continuously since the 1990 s, including "coal reservoirs" (Song et al, 2010; Qian et al, 1997; Li and Zhang, 1990; Wang et al, 1997; Yuan, 1997; Zhou et al, 1997; Zhao et al, 1997; Zhao, 1999; Zhang and Xie, 2002), tectonics and thermodynamic controlling hydrocarbon accumulation (Yang, 1996; Liu et al, 1998; Qin and Song, 1998; Tang, 1998; Ye et al, 1999; Yang and Tang, 2000), sedimentary dynamics controlling the hydrocarbon accumulation (Qin et al, 2000; Jin and Gong, 2001; Sang et al, 2002), and underground hydrodynamics controlling hydrocarbon accumulation (Dai 


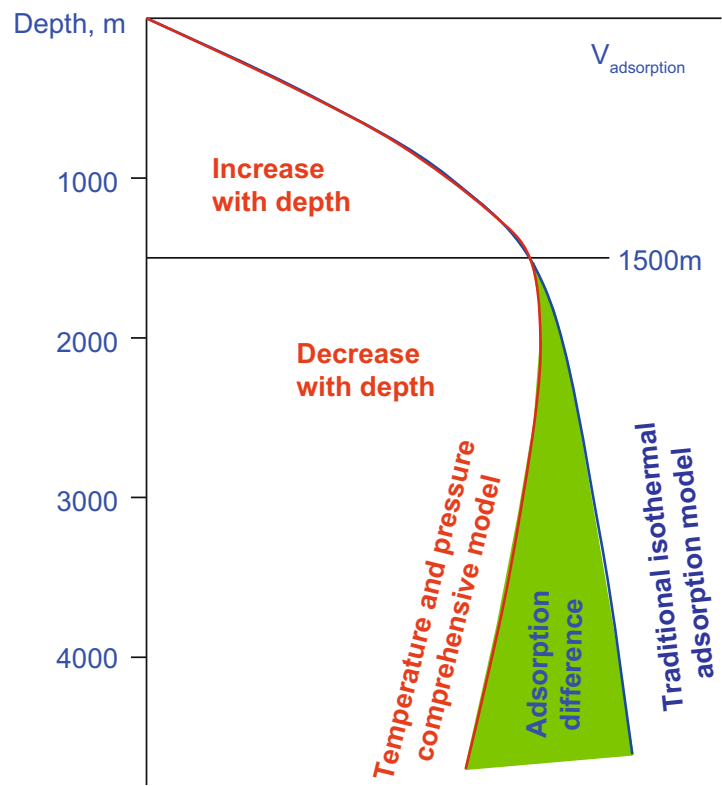

Fig. 5 Comparison between varying temperature and pressure comprehensive model and previous adsorption curve

et al, 1986; Qin et al, 2000; Jin and Gong, 2001; Sang et al, 2002; Wang et al, 1998; 2001; Ye et al, 2001; 2002). The above concepts build a foundation for the development of CBM accumulation theory. However, the previous achievements on CBM accumulation are scattered, and a set of systematic theories has not been set up. Because mediumhigh rank CBM reservoirs experienced more complicated geologic evolution and gas adsorption-desorption processes, there are more scientific problems to be solved. In recent years, based on many experiments and analyses, domestic scholars established a CBM accumulation model for mediumhigh rank coal, revealed three CBM reservoir evolution stages of generation-adsorption, unsaturated adsorption, and desorption-diffusion and preservation, and discussed the dynamical changing regulation of gas adsorptiondesorption. Furthermore, it is proposed that the major controlling factors for CBM accumulation include tectonic evolution, hydrodynamics and sealing conditions, and their most favorable combination determines the CBM syncline enrichment.

\subsection{CBM accumulation process and controlling factors}

The key for CBM accumulation is the gas content of coal beds. Besides the factor of thermal evolution in coal bed, the gas content of a coal reservoir is controlled externally by temperature, pressure and preservation (Ellard et al, 1992; Yee et al, 1993; Laxminarayana and Crosdale, 2002; Gürdal and Yalçın, 2000; Azmi et al, 2006).

\subsubsection{Process of CBM accumulation}

In coal-bearing basins of China, CBM accumulation generally experienced the processes of gas generation and adsorption, adsorption capacity enhancement, gas desorption, diffusion and preservation (Song et al, 2010). During the burial history of coal beds, the increase of strata pressure and geothermal gradient and accompanying tectonic thermal activity in Yanshanian of North China resulted in high thermal evolution of coal beds and enhancement of gas adsorption capacity. There are two stages of gas generation for coal beds and the generated gas existed as an adsorbed form in coal beds, belonging to the generation and gas adsorption stage. In China, both medium-low rank coal and high rank coal experienced deep burial and uplifting in Yanshanian. Because of the decrease of pressure and geothermal gradient, gas generation stopped in coal beds. Some scholars thought that coal bed uplifting resulted in a decrease of CBM adsorption (Zhang et al, 2000). However, the latest research shows that the adsorption volume is mainly affected by temperature below a specific depth, and uplifting process results in an adsorption capacity increase. The adsorption volume above a specific depth is mainly affected by pressure, and the uplifting process belongs to the gas desorption, diffusion and preservation stage (Song et al, 2010).

\subsubsection{Controlling factors of CBM accumulation}

CBM accumulation is actually the process of CBM preservation. CBM diffusion occurs because of tectonic uplifting and change of temperature and pressure, which causes CBM desorption. There are three diffusion paths for desorbed gas. First, free gas diffuses by overcoming capillary pressure of sealing rocks. Second, dissolved gas in water diffuses because of a concentration difference. Third, gas is flushed directly by flowing water (Hong et al, 2005). Therefore, tectonic evolution, hydrodynamics and sealing conditions are dominating factors for CBM accumulation.

Tectonic evolution affects gas content and gas saturation of coal beds directly. The key of CBM accumulation is CBM preservation during coal-bearing basin uplifting. The shallower the uplifted coal bed depth, the worse the $\mathrm{CBM}$ preservation. Thus, in the uplifting process after gas generation, three CBM accumulation types can be identified. For the first type, after the uplifting stage, coal beds kept uplifting continuously to weathering zones, and CBM mainly diffused. The gas content and saturation of coal beds are both too low to meet the condition for CBM accumulation. For the second type, coal beds uplifted below the weathering zones, and the adsorption volume increased. The gas content of coal beds was dependent on the thickness of overlying strata, and the thicker the overlying strata, the higher the gas content. Coal beds are characterized by high gas saturation. For the last type, coal beds subsided after uplifting, the gas content of coal beds relied on subsided thickness of strata with low gas saturation (Song et al, 2005). Among the three CBM accumulation types, the second one is the most favorable for CBM accumulation, with both high gas content and saturation. Furthermore, similar results can be obtained through simulating the effect of pressure change on gas content and saturation (Wang et al, 2004).

Hydrodynamics is also important to CBM preservation. Where there are groundwater flows, underground water carries methane away, reducing the gas content of coal beds. Where the formation water is not moving significantly, coal bed methane pressure changes little from water flowing and the CBM desorption volume is low with relatively high gas content in coal beds. The carbon isotopes of methane become lighter in the gas after water leaching during water solubility experiments, which indicates that the water solubility has 
significant effect on the carbon isotope ratio of CBM (Zhang et al, 2002; Qin et al, 2005). It is clear that water flowing has a great impact on CBM diffusion, and stagnant areas are the most favorable area for CBM accumulation.

Sealing conditions included cap rock, effective thickness of overlying strata and hydraulic sealing. The outcrop areas of coal beds uplifting belongs to open system sealing form with active underground water and large scale of CBM diffusion. A monocline belt is a lateral hydraulic sealing type with relatively good cap rocks. Penetration of atmospheric precipitation can form a hydraulic seal in the updip direction of coal beds, which determines the CBM accumulation. In the deeper part of basin, the sealing type behaved as a closed system. Favorable cap rocks, effective thickness of overlying strata and hydraulic sealing comprise the most advantageous area for CBM accumulation (Hong et al, 2005).

\subsection{Enrichment regulation of $\mathrm{CBM}$}

Research on CBM enrichment of coal-bearing basins reveals $\mathrm{CBM}$ enrichment in syncline structures. For example, in the San Juan Basin of America, gas content increased from the margin to the center of the basin (Choate et al, 1984; Kaiser and Ayers, 1994). Furthermore, in the Qinshui Basin of China, the gas content in the center part of the syncline is higher than that in both flanks (Fig. 6). The gas content of the syncline in the Chengzhuang coalmine, Jincheng area is generally higher than that of the anticline. The gas content in the syncline is higher than $15 \mathrm{~m}^{3} / \mathrm{t}$, while that in the anticline is generally lower than $10 \mathrm{~m}^{3} / \mathrm{t}$ (Wang and Guo, 1996). The gas contents of the axial region of the syncline in the Kaiping area, the Encun well field of Jiaozuo area in Henan province and the Hongyang well field of Shennan area are all higher than those in the flank part of syncline (Song et al, 2010). The regulation of CBM enrichment in syncline is not coincidence, but a comprehensive reflection of optimal gas enrichment conditions which are controlled by tectonic evolution, hydrodynamics and sealing conditions.
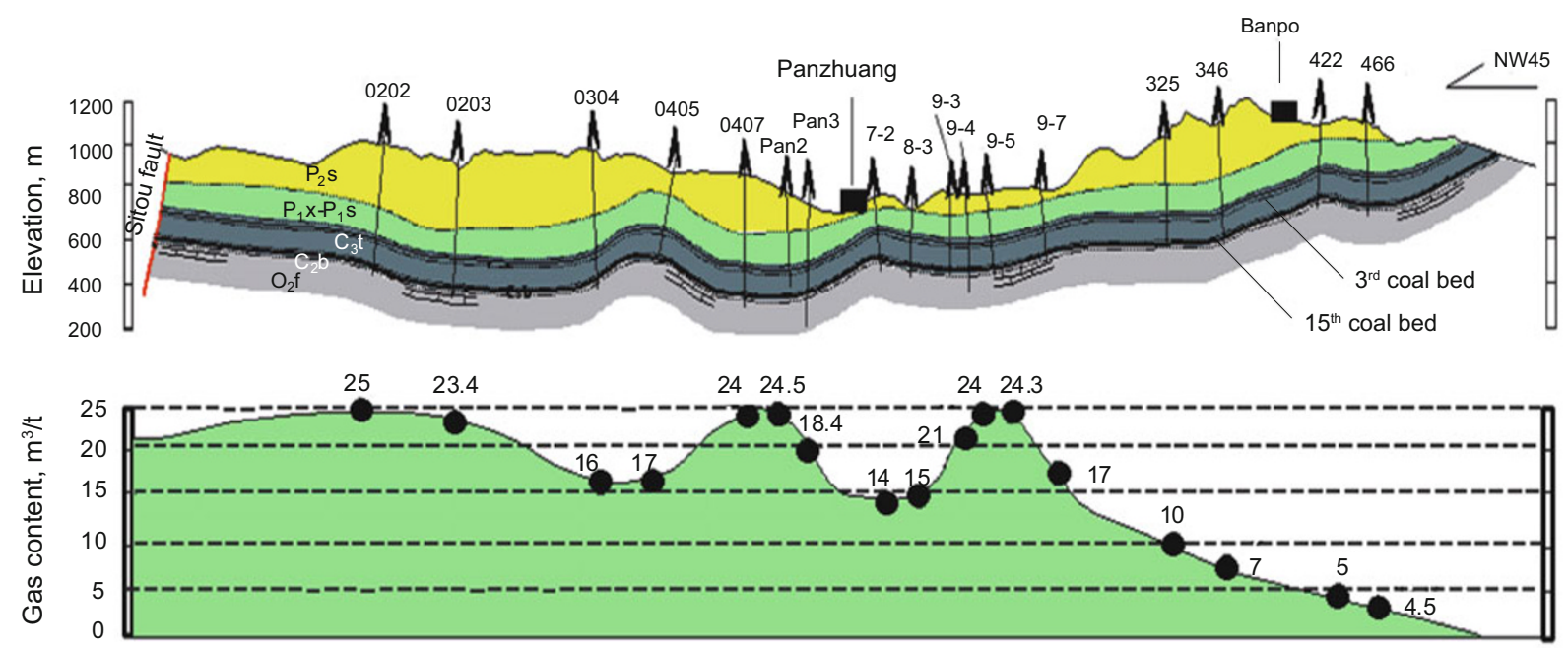

Fig. 6 Relationship between geological structure and gas content of the $3 \#$ coal in the Panzhuang region of Qinshui Basin (Song et al, 2010) $\mathrm{O}_{2}$ f-Fengfeng Formation, $\mathrm{C}_{2}$ b-Benxi Formation, $\mathrm{C}_{3}$ t-Taiyuan Formation, $\mathrm{P}_{1} \mathrm{~s}$-Shanxi Formation, $\mathrm{P}_{1} \mathrm{x}$-lower Shihezi Formation, $\mathrm{P}_{2}$ s-upper Shihezi Formation

CBM accumulation in the axial region of the syncline is much better than that in the flanks of the syncline or coal bed outcropping areas. In the axial region of the syncline, there are several advantages including low uplifting in coal beds, large effective thickness of overlying strata and high hydrostatic pressure, which can preserve enough primary gas content and gas saturation. While in the flank regions of syncline, large uplifts made the coal beds enter the weathering zone or even outcrop. Thus, the effective thickness of overlying strata and hydrostatic pressure became too small to effectively preserve CBM. For example, in the Dacheng area of Hebei province, frequent Yanshanian tectonic events resulted in the thinned effective thickness of overlying strata, worsening CBM preservation conditions, which led to low CBM well production (Wang et al, 2004).

Hydrodynamics in the axial region of the syncline is more favorable for CBM preservation. In the flank region of the syncline or coal bed outcrop area, natural water penetrated deep along the coal beds, flowing in a single direction. Consequently CBM was carried by water, leading to a decrease of gas content in the coal beds (Qin et al, 2005). While in the axial region of syncline, water flowed to the center with high fluid potential and elastic energy (Hubbert, 1953; England et al, 1987) which kept pressure preserved and enhanced adsorption capacity of coal beds. Meanwhile the dissolved CBM carried by water is enriched and accumulated in the axial part of syncline. For example, in the southern part of the Qinshui Basin, atmospheric water exists in the coal beds of the eastern and southern parts, while a drainage divide exists in the coal beds of western and northern parts. Consequently water converges from four directions to the low potential surface. The high gas content areas of $3 \#$ and 15\# coal beds were formed in the converged water area, with the gas content over $15 \mathrm{~m}^{3} / \mathrm{t}$ (Song et al, 2009; Su et al, 2005).

In the axial region of the syncline, the overlying strata tend to be much thicker. Higher strata pressure and good cap rock are all favorable for the CBM adsorption and preservation. At the same time, the axial region of syncline is also the converged water area, where water bodies in both flanks can form hydraulic sealing, and result in the axial 
region of syncline being an advantageous CBM closed system preservation area. For example, from flanks to axial region, the thickness of overlying strata increases in the south of the Qinshui Basin. The water content changed from $\mathrm{HCO}_{3} \cdot \mathrm{SO}_{4}-\mathrm{Ca}$ to $\mathrm{HCO}_{3} \cdot \mathrm{SO}_{4}-\mathrm{K} \cdot \mathrm{Na}$ and $\mathrm{HCO}_{3} \cdot \mathrm{SO}_{4}-\mathrm{Ca} \cdot \mathrm{Mg}$, with the degree of mineralization increasing from $800 \mathrm{mg} / \mathrm{L}$ to $1,000 \mathrm{mg} / \mathrm{L}$, even up to $2,600 \mathrm{mg} / \mathrm{L}$. The effective thickness of overlying strata is in positive correlation with the gas content of coal beds in the Encun well field of the Jiaozuo area and the Hongyang well field of the Shennan area (Song et al, 2010).

To sum up, synclines are generally characterized by centroclinal flowing of underground water, belonging to a lower water potential zone which controlled CBM accumulation. Meanwhile the effective thickness of overlying strata in syncline is large, maintaining high formation pressure systems, which is favorable for CBM adsorption and preservation. Low water potential and high pressure is advantageous for CBM accumulation (Fig. 7).

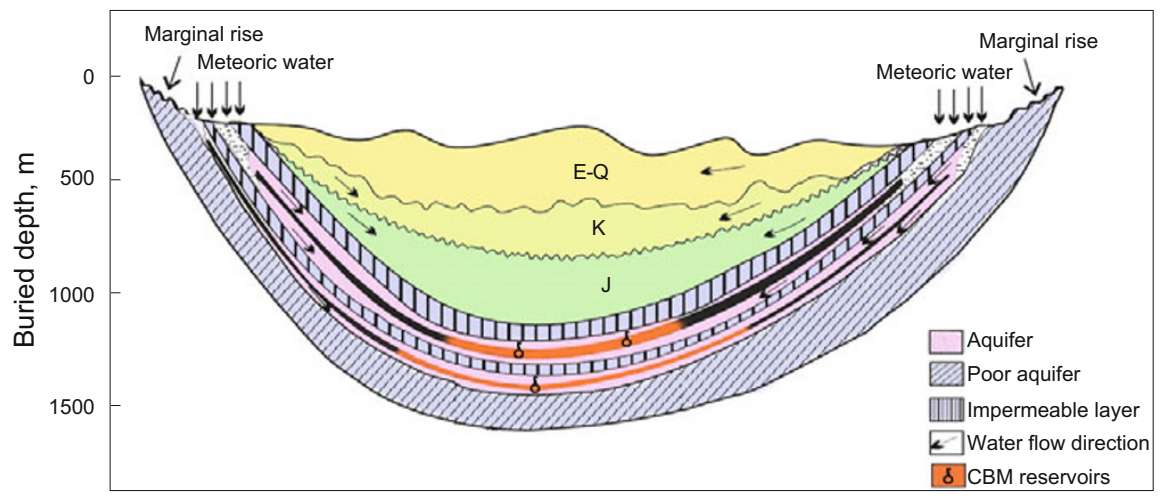

Fig. 7 The model diagram for syncline enrichment of coalbed methane

\section{Conclusions}

1) The geochemical characteristics of CBM differ from conventional natural gas. $\mathrm{CBM}$ is dry gas, its methane content is higher than that in conventional natural gas, and $\delta^{13} \mathrm{C}_{\mathrm{CH}_{4}}$ of $\mathrm{CBM}$ is lighter than that of conventional natural gas.

2) Based on numerous experimental analyses and study of key geochemical indicators, five genetic types of CBM are identified: primary biogenic gas, secondary biogenic gas, thermal degradation gas, pyrolysis gas and mixed genetic gas and the relevant geochemical tracing indicator system is established. The classification of CBM genetic types and development of a tracing indicator system are of great significance for resource estimation of different types of CBM in China and abroad.

3) The adsorption model under varying temperature and pressure indicates that the adsorption of coal seams is controlled by temperature and pressure simultaneously. The dominant control of temperature and pressure on coal seam adsorption varies with depth, i.e. above a specific depth, the adsorption is controlled by pressure, and below the specific depth, temperature plays the dominant role. This model challenges the traditional isothermal adsorption model taking just a single factor into consideration. It is more practical for the estimation of CBM adsorption volumes in different metamorphic degrees and different geological conditions than the traditional isothermal adsorption model. It plays a significant role in evaluation of CBM reservoirs and resources.

4) Tectonic evolution, hydrodynamics and sealing conditions are three major controlling factors for CBM accumulation and enrichment. Synclines are generally characterized by underground water flowing toward the syncline center, low water potential and high hydrostatic pressure. The large effective thickness of overlying strata makes synclines favorable for CBM adsorption and preservation. Furthermore, the theory of CBM enrichment in synclines provides new fields for CBM exploration.

\section{Acknowledgements}

This paper is jointly supported by National Basic Research Program of China (2009CB219600), State Key Laboratory of Petroleum Resource and Prospecting, Key Laboratory of Basin Structure and Hydrocarbon Accumulation of CNPC.

\section{References}

Ayers Jr W B. Coalbed gas systems, resources and production and a review of contrasting cases from the San Juan and Powder River Basins. American Association of Petroleum Geologists Bulletin. 2002. 86(11): 1853-1890

Ayers Jr W B. Geologic and hydrologic controls on the occurrence and producibility of coalbed methane, Fruitland formation, San Juan Basin. GRI Topical Report. 1991. 91: 72

Azmi A S, Yusup S and Muhamad S. The influence of temperature on adsorption capacity of Malaysian coal. Chemical Engineering and Processing. 2006. 45(5): 392-396

Chen C G, Xian X H, Zhang D J, et al. The volume filling theory of the adsorption of methane on anthracite and its characteristics. Journal of Chongqing University (Natural Science Edition). 1998. 21(2): 75 79 (in Chinese)

Choate R, Lent J and Rightmire C T. Upper Cretaceous geology, coal, and the potential for methane recovery from coalbeds in San Juan Basin-Colorado and New Mexico. In: Coalbed methane resources of the United States (Edited by Rightmire C T, Eddy G E and Kirr J N). AAPG Studies in Geology Series. 1984. 17, 216-217

Clarkson C R, Bustin R M and Levy J H. Application of the mono/ multilayer and adsorption potential theories to coal methane adsorption isotherms at elevated temperature and pressure. Carbon. 1997. 35(12): 1689-1705 
Dai J X, Pei X G and Qi H F. Natural Gas Geology in China Vol.1. Beijing: Petroleum Industry Press. 1992. 5-87 (in Chinese)

Dai J X, Qi H F, Song Y, et al. Chinese coalbed gas composition, carbon isotopes type and the causes and significance. Science in China (Series B). 1986. (12): 1317-1326 (in Chinese)

Dai J X, Zou C N, Zhang S C, et al. Discrimination of abiogenic and biogenic alkane gases. Science in China (Series D: Earth Sciences). 2008. 51(12): 1737-1749

Ellard J S, Roark R P and Ayers Jr W B. Geologic controls on coalbed methane production: An example from the Pottsville Formation (Pennsylvanian Age), Black Warrior Basin, Alabama, U.S.A. In: Beamish B and Gamson P D, eds. Symposium on Coalbed Methane Research and Development in Australia. James Cook University of North Queensland. 1992. 45-61

England W A, Mackenzie A S, Mann D M, et al. The movement and entrapment of petroleum fluids in the subsurface. Journal of the Geological Society. 1987. 144(2): 327-347

Fu J M, Liu D H and Sheng G Y. The Coal Formed Hydrocarbon Geochemistry. Beijing: Science Press. 1990 (in Chinese)

Fu X H, Qin Y and Zhang W H. Coupling correlation between highrank coal matrix mechanical effect and coal reservoir permeability. Geological Journal of China Universities. 2003. 9(3): 373-377 (in Chinese)

Gao B, Tao M X, Zhang J B, et al. Distribution characteristics and controlling factors of $\delta^{13} \mathrm{C}_{1}$ value of coalbed methane. Coal Geology \& Exploration. 2002. 30(3): 14-17 (in Chinese)

Gürdal G and Yalçın M N. Gas adsorption capacity of Carboniferous coals in the Zonguldak Basin (NW Turkey) and its controlling factors. Fuel. 2000. 79(15): 1913-1924

Guan D S, Niu J Y, Guo L N, et al. Chinese Unconventional Oil and Gas Geology. Beijing: Petroleum Industry Press. 1995. 8-17 (in Chinese)

Hong F, Song Y, Chen Z H, et al. CBM lost process and geological model. Chinese Science Bulletin. 2005. 50(S1): 121-125 (in Chinese)

Hubbert M K. Entrapment of petroleum under hydrodynamic conditions. AAPG Bulletin. 1953. 37(8): 1954-2026

Jin G F and Gong S L. Relationship between sequence strata and coalbed gas. Coal Geology of China. 2001. 13(2): 29-31 (in Chinese)

Kaiser W R and Ayers Jr W B. Geologic and hydrologic characterization of coalbed-methane reservoirs in the San Juan Basin. SPE Formation Evaluation. 1994. 9(3): 175-184

Laxminarayana C and Crosdale P J. Controls on methane sorption capacity of Indian coals. AAPG Bulletin. 2002. 86(2): 201-212

Li M C and Zhang W J. Shallow Coal-formed Gas Resources of Main Coal Fields in China. Beijing: Science Press. 1990. 1-225 (in Chinese)

Liu D M, Zhang Y G and Tang X Y. The cause of the lighter methane $\delta^{13} \mathrm{C}$ value in coalbed gas. Journal of Jiaozuo Institute of Technology. 1997. 16(2): 89-94 (in Chinese)

Liu H J, Qin Y and Sang S X. Coalbed Methane Geology in Southern Shanxi. Xuzhou: China Mining University Press. 1998. 54-73 (in Chinese)

Liu W H and Xu Y C. Genetic indicators for natural gases. Acta Sedimentologica Sinica. 1996. 14(1): 110-116 (in Chinese)

Qian K, Zhao Q B and Wang Z C. Coalbed Methane Exploration \& Development Theory and Test Technology. Beijing: Petroleum Industry Press. 1997 (in Chinese)

Qin S F, Song Y, Tang X Y, et al. The destructive mechanism of the groundwater flow on gas containing of coal seam. Chinese Science Bulletin. 2005. 50(S1): 99-104 (in Chinese)

Qin Y. Advances in overseas geological research on coalbed gas: Origin and reservoir characteristics of coalbed gas. Earth Science Frontiers. 2005. 12(3): 289-297 (in Chinese)

Qin Y. Advances and reviews on research of coalbed gas geology in China. Geological Journal of China Universities. 2003. 9(3): 339-
358 (in Chinese)

Qin Y and Song D Y. Coalification and Its Paleo-geothermal System in Southern Shanxi. Beijing: Geology Press. 1998. $62-74$ (in Chinese)

Qin Y, Fu X H, Yue W, et al. Relationship between depositional systems and characteristics of coalbed gas reservoir and its caprock. Journal of Palaeogeography. 2000. 2(1): 71-84 (in Chinese)

Ruppel T C, Grein C T and Bienstock D. Adsorption of methane on dry coal at elevated pressure. Fuel. 1974. 53(3): 152-162

Sang S X, Qin Y, Fan B H, et al. Study on sequence stratigraphy applied to coalbed methane resource assessment. Journal of China Coal Society. 2002. 27(2): 113-118 (in Chinese)

Scott A R and Zhou N J. A modified approach to estimating coal and coal gas resources: example from the Sand Wash Basin, Colorado. AAPG Bulletin. 1995. 79(9): 1320-1336

Scott A R, Kaiser W R, Ayers W B, et al. Thermogenic and secondary biogenic gases, San Juan Basin Colorado and New MexicoImplications for coalbed gas producibility. AAPG Bulletin. 1994. 78(8): 1186-1209

Song Y, Liu H L, Liu S B, et al. China's Coalbed Methane Accumulation Geology. Beijing: Science Press. 2010. 5-87 (in Chinese)

Song Y, Liu S B, Zhao M J, et al. Coalbed gas reservoirs: boundary types, main controlling factors of gas pooling, and forecast of gasrich areas. Natural Gas Industry. 2009. 29(10): 5-9 (in Chinese)

Song Y, Qin S F and Zhao M J. Two key geological factors controlling the coalbed methane reservoirs in China. Natural Gas Geoscience. 2007. 18(4): 545-552 (in Chinese)

Song Y, Zhao M J, Liu S B, et al. The influence of tectonic evolution on the accumulation and enrichment of coalbed methane. Chinese Science Bulletin. 2005. 50(S1): 1-5 (in Chinese)

Su X B, Lin X Y, Zhao M J, et al. The upper Paleozoic coalbed methane system in the Qinshui Basin, China. AAPG Bulletin. 2005. 89(1): 81100

Tang D Z. Coal Metamorphism and Evolution of Coal-derived Gas Generation. Beijing: Geology Press. 1998. 58-101 (in Chinese)

Tao M X. The coalbed gas geochemical study situation and development tendencies. Progress in Natural Science. 2005. 15(16): 618-652 (in Chinese)

Tao M X, Shi B G, Li J Y, et al. Secondary biological coalbed gas in the Xinji area, Anhui province, China: Evidence from the geochemical features and secondary changes. International Journal of Coal Geology. 2007. 71(2-3): 358-370

Tao M X, Wang W C, Xie G X, et al. The secondary biological coalbed gas in China. Chinese Science Bulletin. 2005. 50(S1): 14-18 (in Chinese)

Wang C X and Guo G S. Coalbed methane accumulation conditions and the present development situation in mining area of Jincheng. China Coalbed Methane. 1996. (2): 154-157 (in Chinese)

Wang H Y, Liu H L, Liu H Q, et al. The technique and application of coalbed methane reservoir physical simulation. Natural Gas Geoscience. 2004. 15(4): 349-351 (in Chinese)

Wang H Y, Zhang J B, Liu H L, et al. Hydrogeologic feature of coalbed methane reservoir in the southern Qinshui Basin. Coal Geology \& Exploration. 2001. 29(5): 33-36 (in Chinese)

Wang M M, Lu X X, Jin H, et al. Hydrogeological features of Carboniferous-Permian coalbed gas areas in north China. Petroleum Geology \& Experiment. 1998. 20(4): 385-393 (in Chinese)

Wang S W, Chen Z H, Zhang M, et al. Petrophysics of Coal Reservoirs and Selected Exploration Areas of Coalbed Methane. Wuhan: China University of Geosciences Press. 1997. 29-77 (in Chinese)

Weishauptova $\mathrm{Z}$ and Medek J. Bound forms of methane in the porous system of coal. Fuel. 1998. 77(1-2): 71-76

Yang Q. Coal Metamorphism in China. Coal Industry Press. 1996. 184197 (in Chinese)

Yang Q and Tang D Z. Effect of coal metamorphism on methane content 
and permeability of coal in north China. Earth Science (Journal of China University of Geosciences). 2000. 25(3): 273-278 (in Chinese)

Yee D, Seidle J P and Hanson W B. Gas sorption on coal and measurement of gas content. In: Law B E and Rice D D, eds., Hydrocarbons From Coal. AAPG Studies in Geology. 1993. 38: 203218

Ye J P, Qin Y and Lin D Y. China's Coalbed Methane Resource. Xuzhou: China University of Mining and Technology Press. 1999. 1-299 (in Chinese)

Ye J P, Wu Q and Wang Z H. Controlled characteristics of hydrogeological conditions on the coalbed methane migration and accumulation. Journal of China Coal Society. 2001. 26(5): 460-462 (in Chinese)

Ye J P, Wu Q, Ye G J, et al. The forming dynamic mechanism of coalbed methane reservoirs in the southern Qinshui Basin, Shanxi. Geological Review. 2002. 48(3): 319-323 (in Chinese)

Yuan Z W. Types of coalbed methane reservoirs and the factors of high output. Fault-Block Oil \& Gas Field. 1997. 4(2): 9-12 (in Chinese)

Zhang J B, Wang H Y and Zhao Q B. China Coalbed Methane Geology. Xuzhou: China University of Mining and Technology Press. 2000 (in
Chinese)

Zhang X B, Xu Y C, Liu W H, et al. A discussion of formation mechanism and its significance of characteristics of chemical composition and isotope of water-dissolved gas in Turpan-Hami Basin. Acta Sedimentologica Sinica. 2002. 20(4): 705-709 (in Chinese)

Zhang X M. China Coalbed Gas Geology and Resource Assessment. Science Press. 2002 (in Chinese)

Zhang X M and Xie G X. Main technical problems and strategy faced in the CBM development in China. Coal Geology \& Exploration. 2002. 30(2): 19-22 (in Chinese)

Zhao Q B, Li W Z and Sun F J. Distribution and accumulation regularity for coalbed methane in China. Acta Petrolei Sinica. 1997. 18(4): 1-6 (in Chinese)

Zhao Q B. Coalbed Gas Geology and Exploration Techniques. Beijing: Petroleum Industry Press. 1999. 13-44 (in Chinese)

Zhou Y Z, Hao N and Xiao B. Research on the coalbed gas exploration and development program. Fault-Block Oil \& Gas Field. 1997. 4(4): 20-23 (in Chinese)

(Edited by Hao Jie) 